\title{
Implementation of Heading Angle and Depth Keeping Control of ROV with Multiple Thrusters by Thrust Allocation
}

\author{
Suk-Min Yoon", Chong-Moo Lee* and Kihun Kim ${ }^{*}$ \\ "Marine Robotics Laboratory, KRISO, Daejeon, Korea \\ 다수의 추진기를 지닌 ROV의 추력배분을 통한 정지 상태에서의 \\ 선수각 및 수심 제어 구현 \\ 윤석민 ${ }^{*}$ 이종무 ${ }^{*}$ 김기훈(1) \\ "선박해양플랜트연구소
}

KEY WORDS: Light work class ROV 경작업용 ROV, Thrust allocation 추력배분, Thruster configuration matrix 추진기 배치 행렬, Redundant actuating system 과구동기 시스템, Propulsion system 추진 시스템

\begin{abstract}
This study deals with the heading angle and depth keeping control technique for an ROV with multiple horizontal and vertical thrusters by thrust allocation. The light work class ROV URI-L, which is under development at KRISO, is a redundant actuating system with multiple thrusters that are larger than the ROV's degree of freedom. In the redundant actuating system, there are several solutions for a specific ROV motion to be performed. Therefore, a thrust allocation algorithm that considers the entire propulsion system should be regarded as important. First, this paper describes the propulsion system of the ROV and introduces the thrust allocation method of each motion controller. In addition, the performance of the controller is examined using a heading angle and depth keeping control test in a stationary state.
\end{abstract}

\section{1. 서 론}

선박해양플랜트연구소와 레드원테크놀로지(주)는 수중건설작 업을 지원하기위한 경작업용 ROV(Remotely operated vehicle), URI-L을 개발 중이다. 여기서 경작업은 수중 건설작업에서 요 구되는 다양한 소규모 작업(경량물체 이동, 소형 작업툴을 이용 한 작업, 수중지형정보 제공 등)을 의미하며, 경작업용 ROV는 원활한 수중작업을 위해 특정 자세 유지 및 다양한 동작 수행 능력이 요구된다. 이를 위해, URI-L은 움직일 수 있는 자유도보 다 추진기 수가 많은 과구동기 시스템(Redundant actuating system)으로 개발되었다. 이러한 과구동기 시스템의 경우 특정 운동을 수행하기 위한 다양한 해법이 존재하므로, 추진 시스템 (Propulsion system) 전체를 고려한 추력배분(Thrust allocation) 알 고리즘이 중요하게 다루어져야 한다.

과구동기 시스템은 다음과 같은 특징을 가지고 있다(Johansen and Fossen, 2013).
(1) 내고장성(Fault tolerance)과 추력배분을 위한 여분(Redundancy) 의 작동기를 보유하고 있다.

(2) 단일 작동기로 수행되는 운동을 여러 작동기의 작은 제어 입력으로 동일하게 수행 가능하므로, 단일 작동기의 부하를 줄 일 수 있다.

(3) 과구동기 시스템은 다수의 작동기를 가지지만, 추력을 배 분하는 상위 제어기에서 전체 시스템의 자유도 수와 동일한 힘 과 모멘트 $\tau$ 로 표현 가능하다. 이 경우 상위 제어기는 $\tau$ 의 제약 조건을 고려해야 한다.

(4) 원하는 운동을 수행하기 위한 개별 운동에 대한 별도의 하위 제어기가 존재 한다. 특정 작동기는 여러 하위 제어기에 관여할 수 있으므로 중복되어 사용될 수 있다. 이 경우 특정 작 동기에 과도한 부하가 발생할 가능성이 있다.

(5) 최적 제어의 틀에서 가중치 행렬을 적절히 선택한 추력배 분을 통해 제어 성능의 손실 없이 요구하는 운동 제어가 가능 하다(Harkegard and Glad, 2005).

Received 7 August 2017, revised 14 February 2018, accepted 14 February 2018

Corresponding author Kihun Kim: +82-42-866-3814, khkim@kriso.re.kr ORCID: https://orcid.org/0000-0001-5852-3347

It is noted that this paper is revised edition based on proceedings of KSOE 2017 in Busan.

This is an open access article distributed under the terms of the creative commons attribution non-commercial license (http://creativecommons.org/licenses/by-nc/3.0) which permits unrestricted non-commercial use, distribution, and reproduction in any medium, provided the original work is properly cited. 
과구동기 시스템의 제어력을 할당하기 위한 추력배분은 항공 (Oppenheimer and Doman, 2007) 및 우주(Henrik, 2005) 그리고 선박(Berge and Fossen, 1997; Fossen and Johansen, 2006; Ji and Kim, 2012) 및 수중로봇(Garus, 2004; Whitcomb and Yoerger, $1999)$ 분야뿐만 아니라, 자동차, 보행로봇, 멀티로봇(Pedrami et al., 2009)과 같은 다른 여러 분야로 확대되고 있는 추세이다. 또 한 특정 작동기에 문제 발생시 나머지 작동기에 제어력을 재할 당하는 추력 재배분 기법에 대해 많은 연구가 이루어지고 있다 (Shen et al., 2017).

본 논문에서는 10 개의 추진기를 가지는 경작업용 ROV의 6 자 유도 운동을 구현하기 위한 방법에 대해 다루고자 한다. 2장에 서 다수의 수직 - 수평 추진기를 가지는 경작업용 ROV와 그 추 진 시스템에 대해서 설명한다. 3장에서는 과구동기 시스템인 $\mathrm{ROV}$ 의 운동을 제어하기 위해 설계된 제어기에 대해 소개한다. 이상적인 상태의 ROV를 대상으로 추진기 배치 행렬을 이용한 상위 추력배분 제어기와 ROV의 개별 운동을 제어하기 위한 하 위 운동 제어기에 대해 설명하고 전체 제어기 구성을 제시한다. 4장에서는 이상적인 상태를 가정하고 설계된 제어기에 대한 성 능을 확인하기 위해 ROV가 정지한 상태에서 선수각 및 수심 제어를 동시에 수행한 실험 결과를 고찰한다.

\section{2. 다수의 수직 · 수평 추진기를 지닌 ROV}

경작업용 ROV는 수중 건설에 필요한 다양한 경작업, 모니터 링, 시공전후 해저면 정밀 매핑, 각종 유지보수 등의 작업이 가능 하도록 개발 중인 수중로봇으로 그 외형은 Fig. 1 과 같다. 본 연구 의 ROV는 수중의 경작업을 위한 로봇 팔(Manipulator)을 전방에 2개 장착하였으며 각종 항법 센서와 주변 환경을 인지하기 위한 어라운드 뷰 카메라와 장애물 탐지 소나, 전방 주사 이미징 소나 와 멀티빔 이미징 소나를 탑재하고 있다. ROV의 자세한 사양은 Table 1과 같다. 천해역에서 주기적으로 발생하는 대부분의 조류 는 $2 \mathrm{knots}(1.03 \mathrm{~m} / \mathrm{s})$ 정도이므로 최대전진속도는 $2.5 \mathrm{knots}(1.29 \mathrm{~m} / \mathrm{s})$ 로 설계되었다.

$\mathrm{ROV}$ 의 운동 성능을 확보하기 위해 6자유도보다 많은 수의 추진기를 이용해 설계된 유영속도로 움직이고, 정지된 자세를 유지할 수 있도록 제작되었다. 이를 위한 ROV의 추진 시스템



Fig. 1 Appearance of light work class ROV
Table 1 Specifications of light-work-class ROV

\begin{tabular}{cl|ll}
\hline \hline \multicolumn{1}{c|}{ Item } & \multicolumn{1}{c}{ Specifications } & Item & Specifications \\
\hline Design depth & $3,000 \mathrm{~m}$ & Length & $2.3 \mathrm{~m}$ \\
Working depth & $2,500 \mathrm{~m}$ & Width & $1.27 \mathrm{~m}$ \\
Forward speed & 2.5 knots $(1.29 \mathrm{~m} / \mathrm{s})$ & Height & $1.3 \mathrm{~m}$ \\
Vertical speed & 2.0 knots $(1.03 \mathrm{~m} / \mathrm{s})$ & Weight & $1.48 \mathrm{ton}$ \\
Lateral speed & 2.0 knots $(1.03 \mathrm{~m} / \mathrm{s})$ & Payload & $110 \mathrm{kgf}$ \\
\hline
\end{tabular}



Fig. 2 Configuration of propulsion system for LWC ROV

Table 2 Specifications of vertical \& horizontal thrusters

\begin{tabular}{cll}
\hline \hline & \multicolumn{1}{c}{ Vertical } & \multicolumn{1}{c}{ Horizontal } \\
\hline Model & Tecnadyne 1060 & Tecnadyne 2020 \\
Electric power & $2.7 \mathrm{kw}$ & $5.5 \mathrm{kw}$ \\
Forward thrust & $105 \mathrm{lbf}(48 \mathrm{kgf})$ & $250 \mathrm{lbf}(116 \mathrm{kgf})$ \\
Reverse thrust & $65 \mathrm{lbf}(29.5 \mathrm{kgf})$ & $1601 \mathrm{bf}(73 \mathrm{kgf})$ \\
\cline { 2 - 3 } Feature & DC brushless thruster \\
& Stainless steel propellers \\
& Analog or RS485 speed control \\
\hline
\end{tabular}

(Propulsion system)은 Fig. 2와 같이 4개의 수직(Vertical) 추진기 와 6개의 수평(Horizontal) 추진기로 구성되어 있다. 수직 및 수 평 추진기는 Tecnadyne의 전기모터 추진기로 자세한 사양은 Table 2와 같다. 정지된 상태에서 로봇 팔을 이용하여 작업할 경우 $\mathrm{ROV}$ 의 자세에 영향을 줄 수 있기 때문에, 수직 운동에 필 요한 추력을 용량이 작은 4대의 추진기로 분산 확보하여 종경 사각과 횡경사각에 대한 가제어성을 확보하였다. ROV가 수평 운동을 하기 위해서는 4대의 추진기만으로도 가능하지만, 최대 전진속도를 달성하기 위해 전진방향 추력을 증가시키는 수평 추진기 2 대가 후미에 배치되었다. 그리고 모든 추진기는 프로펠 러 회전에 대해 반작용으로 발생되는 모멘트를 상쇄시키기 위 해 인접한 추진기의 프로펠러 날의 각도(Blade angle)가 서로 상 반되도록 설계되었다(Lee et al., 2017).

Fig. 3은 본 연구에서 다루고 있는 ROV의 좌표계를 도시한 결과이며, 수직 추진기와 수평 추진기는 각각 Fig. 4 및 Fig. 5와 같이 배치되어 있다. 여기서 수직 추진기에 경사각을 준 이유는 $\mathrm{ROV}$ 선체와 추진기의 간섭을 최소화하기 위함이다. 본 연구에 


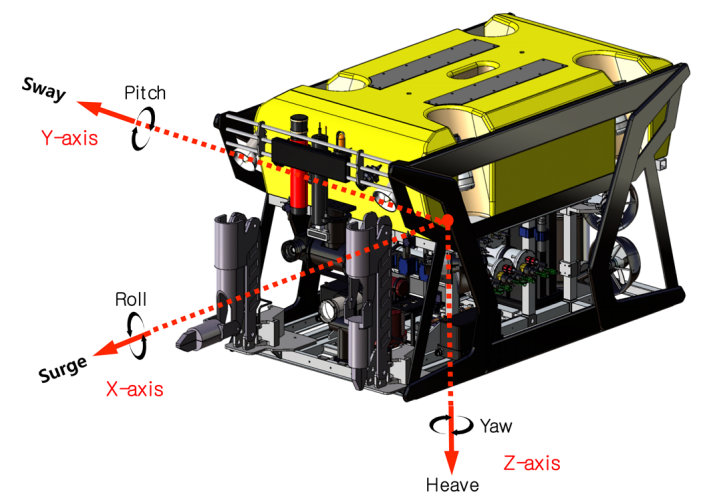

Fig. 3 Coordinate system of 6DOF ROV
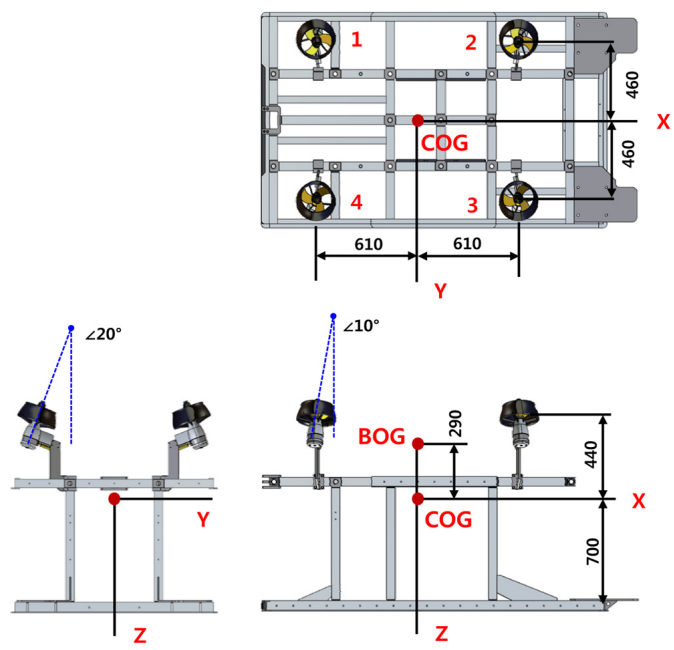

Fig. 4 Geometry of vertical thrusters
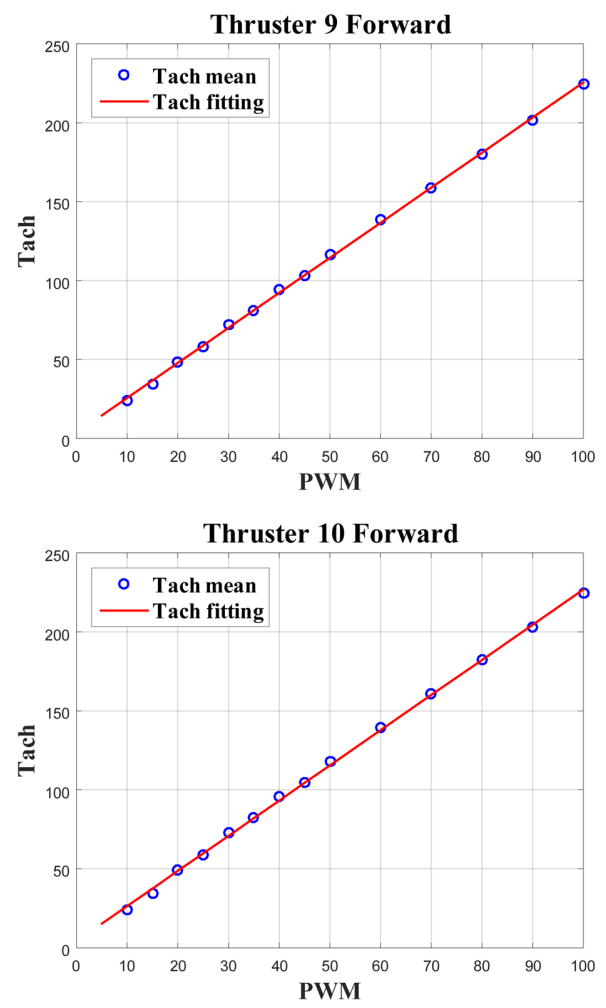

Fig. 6 PWM vs. Tachometer graph of $9 \& 10$ thrusters


Fig. 5 Geometry of horizontal thrusters

서는 ROV의 수직 추진기와 수평 추진기는 각각 수직 운동과 수평 운동에만 영향을 준다고 가정하였다. 여기서, 수직 운동은 Heave, Roll, Pitch 방향의 운동을 의미하고, 수평 운동은 Surge, Sway, Yaw 방향의 운동을 의미한다. 또한, 수평 추진기인 9, 10 번 추진기는 전진 방향 속도에만 관여한다고 가정하였다. 즉, Surge 운동 방향의 부스터 개념으로 운용되어진다.

추진기의 특성을 확인하기 위해 추진기의 $\mathrm{PWM}(\mathrm{Pulse}$ width modulation) 입력에 대한 RPM(Revolution per minute) 출력 실험



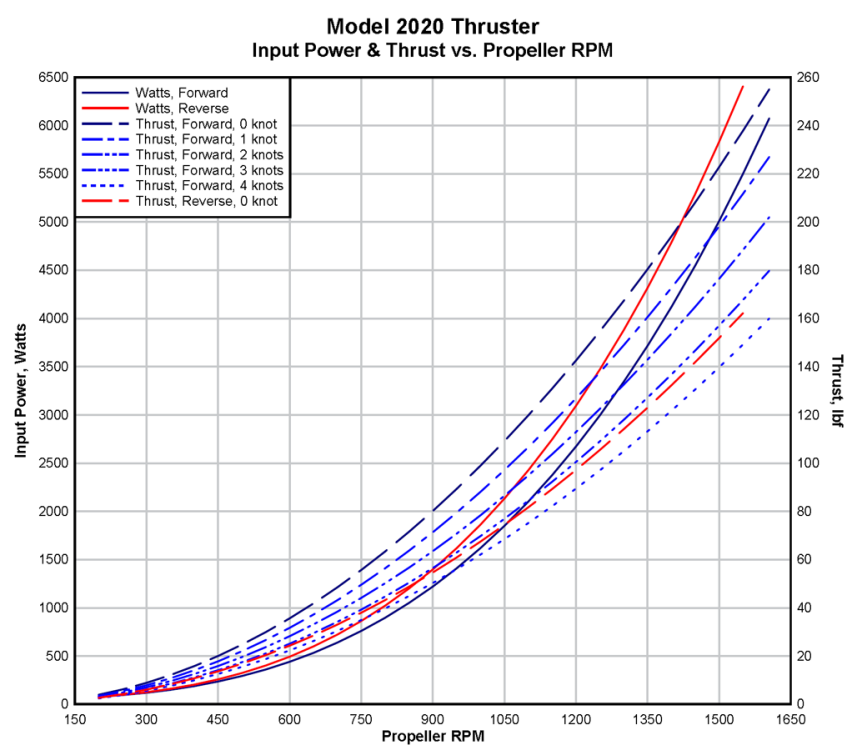

Fig. 7 RPM vs. Thrust graph of horizontal thruster

을 수행하였다(Yoon et al., 2017). 실제 추진기 출력은 초단위의 회전속도계(Tachometer)로 측정되므로 식 (1)을 통해 RPM으로 변환된다.

$$
\begin{aligned}
& \text { Vertical thruster : } \mathrm{RPM}=\text { Tach } \times 60 / G_{v} \\
& \text { Horizontal thruster : } \mathrm{RPM}=\text { Tach } \times 60 / G_{h}
\end{aligned}
$$

여기서, $G_{v}$ 및 $G_{h}$ 는 수직 및 수평 추진기의 1회전 당 측정되는 회전속도계의 값을 의미하며, 각각 6 과 20.1 의 상수 값을 가진다.

Fig. 6 은 9,10 번 추진기의 입출력 실험 결과를 나타내고 있으 며, 이를 통해 PWM 입력에 대한 RPM 출력이 선형이고 정/역 방향에서 동일함을 확인할 수 있다. 그러나 RPM 출력의 선형성 과 별도로 추진기 프로펠러의 방향에 따라 추진기의 추력이 달 라지므로, 프로펠러 정/역방향에 대한 추력 그래프를 적용하여 이를 보정할 필요가 있다. Fig. 7은 경작업용 ROV의 수평 추진 기인 Model 2020의 RPM 입력에 대한 Thrust 출력 그래프이다. 동일한 RPM에서 역방향 추력은 정방향 추력의 $70 \%$ 정도로 관 측되므로, 동일한 추력을 발생시키기 위한 보상이 필요하다.

\section{3. 추력배분 및 제어}

경작업용 $\mathrm{ROV}$ 는 작동기가 움직일 수 있는 자유도보다 많은 과구동기 시스템으로, 이러한 경우 추진기를 개별적으로 제어 하기 보다는 통합하여 관리하는 것이 유리하다. 추력배분은 이 러한 추진기 통합관리 방법 중에 하나이다(Craven et al., 1998). 본 연구에서는 추력배분을 위한 이상적인 ROV의 상태를 다음 과 같이 가정하고 제어기를 설계하였다.

(1) ROV 선체와 추진기는 독립되어 있으며, 상호 간의 간섭 은 없다.

(2) 수직 운동과 수평 운동은 독립적인 운동이다.

(3) 수직 운동 및 수평 운동은 각각 수직 추진기와 수평 추 진기에 의존적이다.
(4) ROV의 운동은 추진기의 추력 한계 내에서 구현 가능하다.

(5) $\mathrm{ROV}$ 의 형상은 좌우 대칭이다.

$\mathrm{ROV}$ 의 수직 운동 $\tau_{v}$ 와 수평 운동 $\tau_{h}$ 는 수직 및 수평 추진기 의 추력 벡터 $f_{v}$ 및 $f_{h}$ 을 이용하여 식 (2)와 같이 표현할 수 있 다(Garus, 2004).

$$
\begin{aligned}
\tau_{v} & =\left[\begin{array}{lll}
F_{z} & M_{x} & M_{y}
\end{array}\right]^{T}=T_{v} f_{v} \\
\tau_{h} & =\left[\begin{array}{lll}
F_{x} & F_{y} & M_{z}
\end{array}\right]^{T}=T_{h} f_{h}
\end{aligned}
$$

여기서, $f_{v}=\left[f_{1} f_{2} \cdots f_{4}\right]^{T}, f_{h}=\left[f_{5} f_{6} \cdots f_{8}\right]^{T}$ 이며, $T_{v}$ 와 $T_{h}$ 는 각 각 수직 및 수평 추진기 배치 행렬(Thruster configuration matrix) 을 의미하고 식 (3)과 같이 계산된다.

$$
\begin{aligned}
& T_{v}=\left[\begin{array}{ccc}
\sin \alpha_{y 1} \cos \alpha_{z 1} & \cdots & \sin \alpha_{y 4} \cos \alpha_{z 4} \\
d_{y 1} \sin \left(\beta_{y 1}\right) & \cdots & d_{y 4} \sin \left(\beta_{y 4}\right) \\
d_{z 1} \sin \left(\beta_{z 1}\right) & \cdots & d_{z 4} \sin \left(\beta_{z 4}\right)
\end{array}\right] \\
& T_{h}=\left[\begin{array}{ccc}
\cos \alpha_{x 5} & \cdots & \cos \alpha_{x 8} \\
\sin \alpha_{x 5} & \cdots & \sin \alpha_{x 8} \\
d_{x 5} \sin \left(\beta_{x 5}\right) & \cdots & d_{x 8} \sin \left(\beta_{x 8}\right)
\end{array}\right]
\end{aligned}
$$

여기서, 아래 첨자인 $x, y, z$ 는 각각 $\mathrm{XY}$ 평면, $\mathrm{YZ}$ 평면, $\mathrm{ZX}$ 평면을 의미한다. $d_{x i}$ 는 $\mathrm{XY}$ 평면에서 무게중심 $(\mathrm{COG})$ 으로부터 $i$ 번째 추진기까지의 거리이고, $\alpha_{x i}$ 는 $\mathrm{XY}$ 평면에서 $\mathrm{X}$ 축에 대한 $i$ 번째 추진기의 추진방향의 각도이며, $\beta_{x i}$ 는 $\mathrm{XY}$ 평면에서 추진 기의 추진방향에 대한 무게중심과 추진기를 이은 선분의 각도 로 식 (4)과 같이 계산된다.

$$
\beta_{x i}=\pi-\left(\alpha_{x i}-\gamma_{x i}\right)
$$

여기서, $\gamma_{x i}$ 는 $\mathrm{XY}$ 평면에서 $\mathrm{X}$ 축에 대한 무게중심과 추진기를 이은 선분의 각도이다. $\alpha_{x i}, \beta_{x i}, \gamma_{x i}$ 의 기하학적 관계는 Fig. 8 과 같이 표현된다.

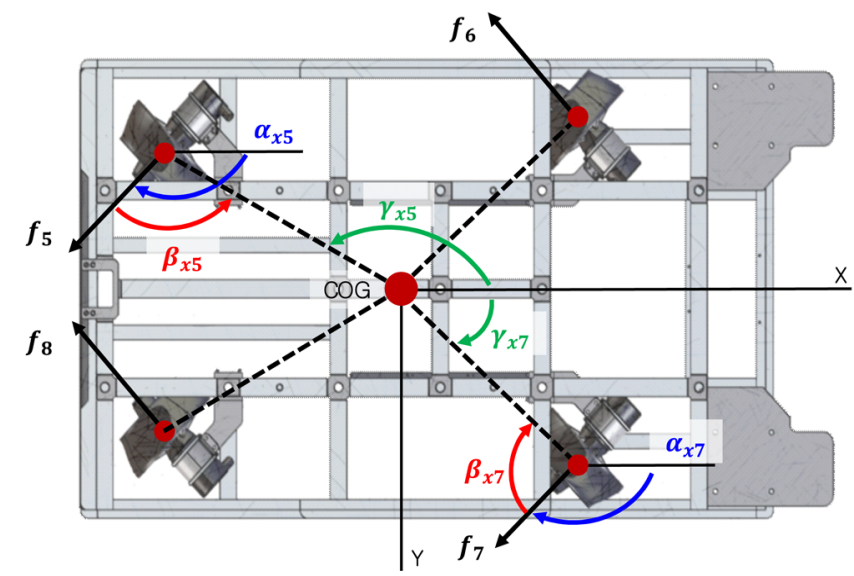

Fig. 8 Definition of $\beta_{x i}$ in XY plane 
계획된 수직 및 수평 운동을 개별 추진기의 추력으로 변환하 기 위해서는, 식 (3)의 추진기 배치 행렬 $T_{v}$ 와 $T_{h}$ 을 이용하여 식 (2)의 추력 벡터 $f_{v}$ 및 $f_{h}$ 을 계산해야한다. $\mathrm{ROV}$ 의 계획된 수 직 및 수평 운동이 $\tau_{v}$ 및 $\tau_{h}$ 일 때, 추력의 한계를 가지는 추진기 의 추력배분 문제는 다음과 같이 표현된다(Fossen and Johansen, 2006).

$$
\begin{array}{ll}
\operatorname{minimize} & J=\frac{1}{2} f_{v}^{T} H_{v} f_{v} \\
\text { subject to } T_{v} f_{v}-\tau_{v}=0 & \\
\text { minimize } & J=\frac{1}{2} f_{h}^{T} H_{h} f_{h} \\
\text { subject to } T_{h} f_{h}-\tau_{h}=0
\end{array}
$$

이때, $H_{v}$ 와 $H_{h}$ 는 가중행렬로 Positive definite matrix이다.

가중행렬을 $H_{v}=H_{h}=I$ 라고 가정하면, 식 (6)을 이용하여 계 산된 $f_{v}$ 와 $f_{h}$ 는 식 (5)의 최적해가 된다.

$$
\begin{aligned}
& f_{v}=T_{v}^{T}\left(T_{v} T_{v}^{T}\right)^{-1} \tau_{v}=T_{v}^{+} \tau_{v} \\
& f_{h}=T_{h}^{T}\left(T_{h} T_{h}^{T}\right)^{-1} \tau_{h}=T_{h}^{+} \tau_{h}
\end{aligned}
$$

여기서, ${ }^{+}$는 의사역행렬을 의미하고, 식 (6)은 ROV의 운동을 구현하기 위해 추진기의 추력을 배분하는 상위 제어기 역할을 수행한다.

이러한 최적화 방법은 $f_{v}$ 와 $f_{h}$ 가 추진기의 추력 범위 내에 존 재할 때에만 유효하며, 한계를 벗어나는 경우 최적해에 근접하 기 위한 재배분 기법이 필요하다. 본 연구에서는 추력 범위 내 에서 운동 구현이 가능하다고 가정하고, 의사역행렬을 이용하 여 $T_{v}^{+}$및 $T_{h}^{+}$을 구하였다.

$\mathrm{ROV}$ 추진기의 기하학적 배치(Fig. 4 및 Fig. 5)를 이용하여 추 진기 배치 행렬의 의사역행렬을 구한 결과는 다음과 같다.

$$
\begin{aligned}
T_{v}^{+} & =\left[\begin{array}{ccc}
0.2701 & -0.5170 & 0.3989 \\
0.2701 & -0.5170 & -0.3989 \\
0.2701 & 0.5170 & -0.3989 \\
0.2701 & 0.5170 & 0.3989
\end{array}\right] \\
T_{h}^{+} & =\left[\begin{array}{ccc}
0.3536-0.3484 & 0.3449 \\
0.3536 & 0.3587 & 0.3449 \\
0.3536 & -0.3587 & -0.3449 \\
0.3536 & 0.3484 & -0.3449
\end{array}\right]
\end{aligned}
$$

과구동기 시스템인 경작업용 ROV의 운동을 제어하기 위해 추력을 배분하는 상위 제어기와 원하는 운동을 수행하기 위한 하위 제어기를 구현하였으며, 제어 블록선도는 Fig. 9와 같이 표 현된다. 식 (6)의 상위 제어기에서 계산된 추진기의 추력 벡터 에 의해 ROV는 운동하게 되고 그 결과가 각종 센서의 의해 계 측된다. ROV의 개별 운동을 담당하는 하위 제어기는 제어목표 치와 현재 데이터를 비교하여 목표치를 달성하기 위해 요구되 는 ROV의 운동을 계산한다. 본 연구에서는 ROV의 선수각 및 수심을 제어하기 위한 하위 제어기를 대표적인 피드백 제어방 법인 PD(Proportional-derivative) 제어기를 적용하여 설계하였다.

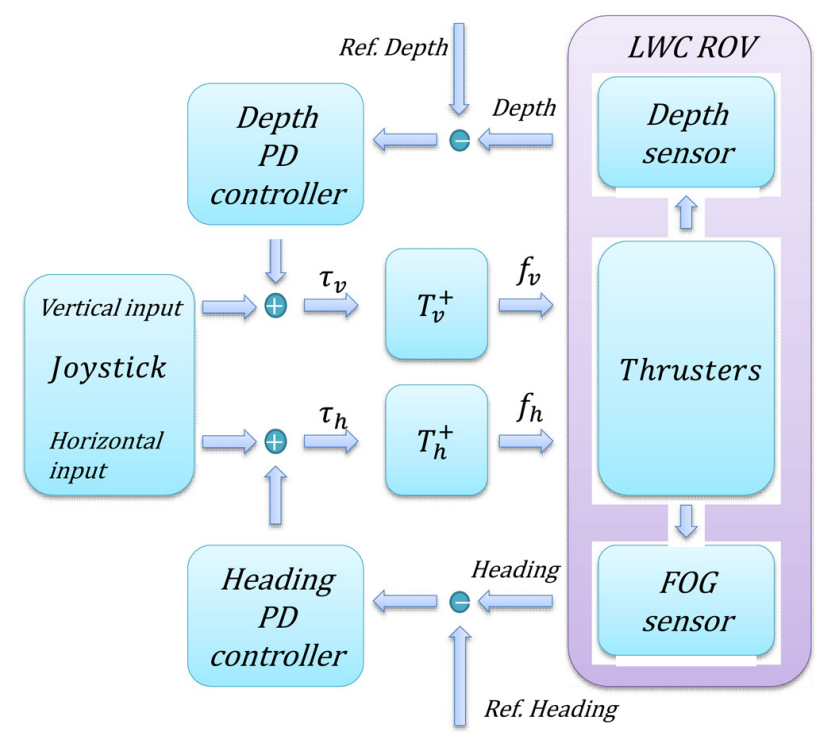

Fig. 9 Block diagram for heading and depth control

Table 3 Specifications of heading and depth sensors

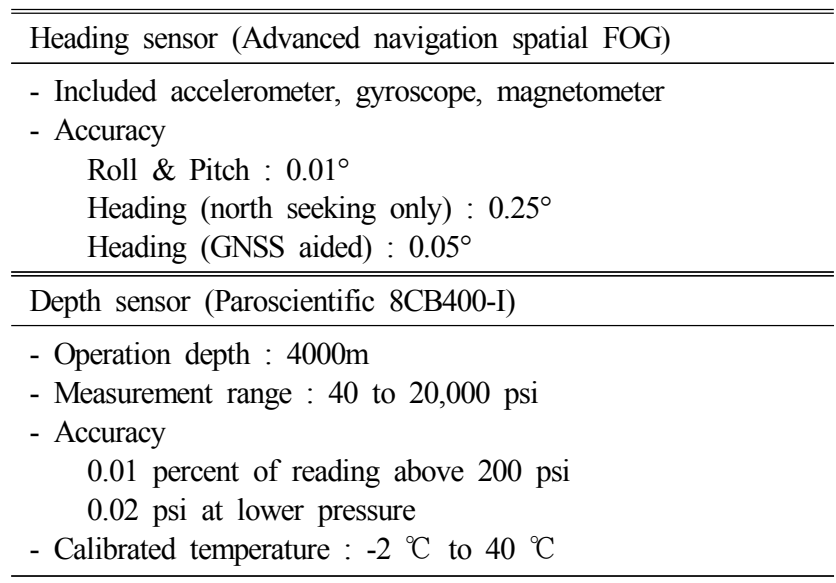

이때, 제어이득(Gain)은 시행 착오법(Trial and error method)을 통해 선정하였으며, 선수각 및 수심을 측정하기 위한 센서의 사 양은 Table 3 과 같다. 제어 블록선도에서 상위 제어기의 입력 $\tau_{v}$ 및 $\tau_{h}$ 는 하위의 $\mathrm{PD}$ 제어기 입력과 외부의 조이스틱 입력의 합 으로 생성되도록 설계되었다. 이는 ROV의 선수각과 수심은 PD 제어기를 통해 자동으로 유지하면서, ROV의 Roll, Pitch 및 Surge, Sway 방향의 운동을 운용자가 조이스틱을 통해 조작 할 수 있다는 것을 의미한다. 이 경우 특정 작동기는 중복되어 사 용되어 과도한 부하가 발생할 가능성이 있지만, 본 연구에서는 추진기의 추력 한계 내에서 ROV가 운동한다고 가정한다.

\section{4. 성능시험 결과}

경작업용 $\mathrm{RO}$ 의 추력배분 상위 제어기와 선수각 및 수심 제어 를 위한 하위 제어기의 성능을 확인하기 위해, Fig. 10 과 같이 포항의 수중로봇복합실증센터(UTEC)에서 수조시험을 수행하였 다. 성능시험은 이상적인 상태의 $\mathrm{ROV}$ 를 대상으로 설계된 제어 기의 실제 성능을 분석하기 위해, 정지 상태에서 단일 수직운동 
Implementation of Heading Angle and Depth Keeping Control of ROV with Multiple Thrusters by Thrust Allocation 73

과 단일 수평운동을 다음의 2가지 방법으로 수행하였다.

(1) 수심 목표치 고정 상태에서 선수각 목표치 변경(Fig, 11)

(2) 선수각 목표치 고정 상태에서 수심 목표치 변경(Fig. 12)

Fig. 11은 목표 수심이 $2.5 \mathrm{~m}$ 로 고정 된 상태에서 목표 선수각 을 변경한 결과이다. 선수각의 목표치는 $110^{\circ}$ 와 $270^{\circ}$ 로 반복적 으로 설정되었으며, 약 15 초 이후에 $5^{\circ}$ 이내로 목표치에 수렴하

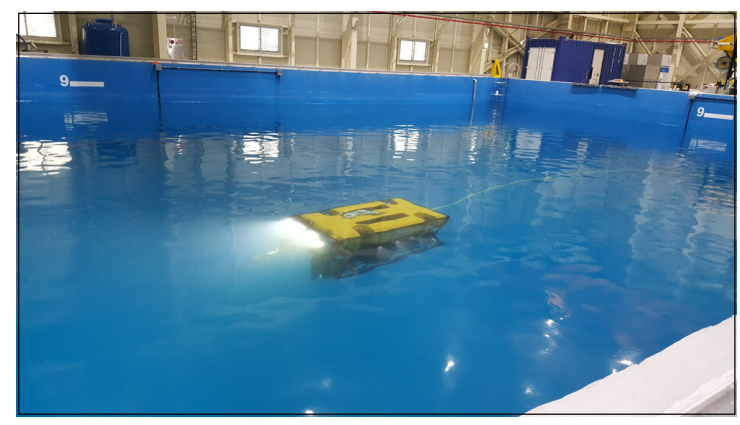

Fig. 10 Test scene in basin of UTEC
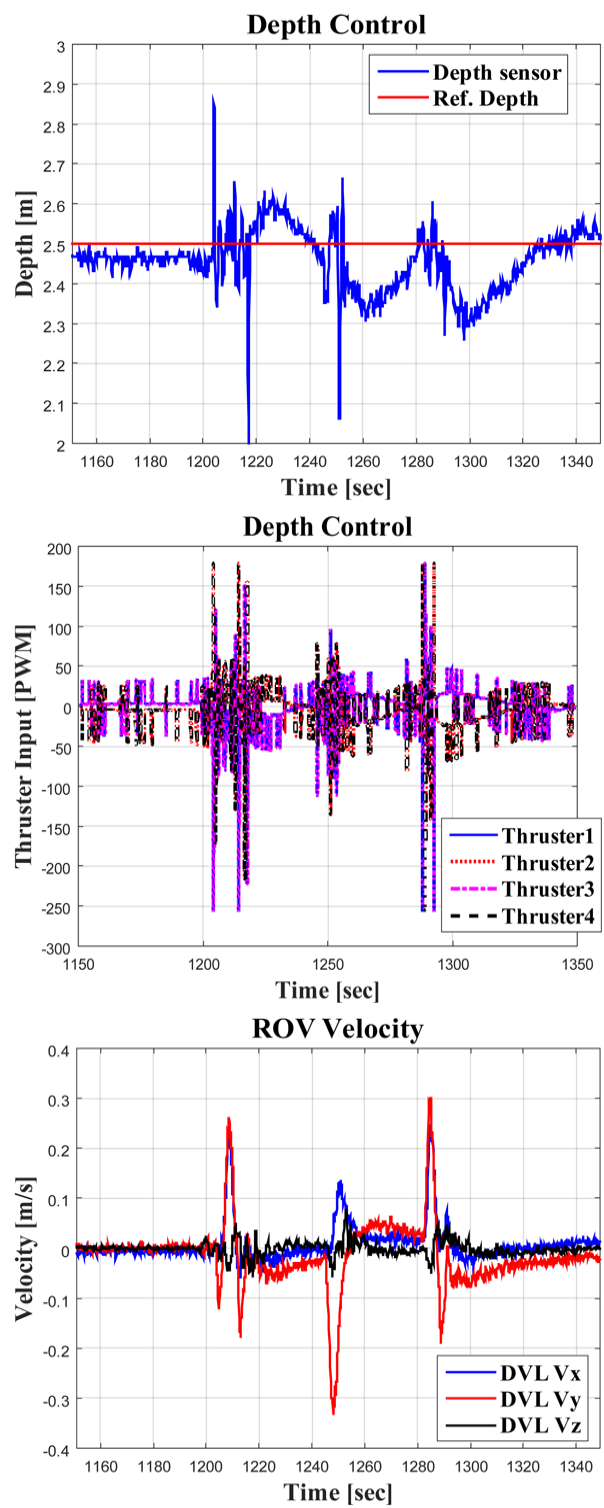

였음을 확인할 수 있다. 이때, 수심은 $\pm 0.2 \mathrm{~m}$ 정도의 오차로 제 어되고 있음을 관측할 수 있다. 참고로 1200 초 부근에서 선수각 의 목표치가 일시적으로 $27^{\circ}$ 로 설정되어 $\mathrm{ROV}$ 가 실제로 반응하 였다. 제어입력의 경우 역방향의 최대 추력을 기준으로 정방향 의 추력을 제한하였기 때문에 정역방향의 PWM 값이 다르게 나 오고 있다. 수심의 변화 없이 선수각만 변경했기 때문에, 속도

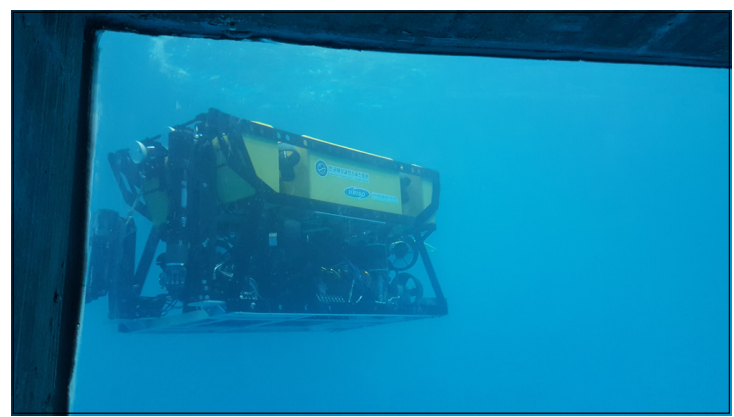


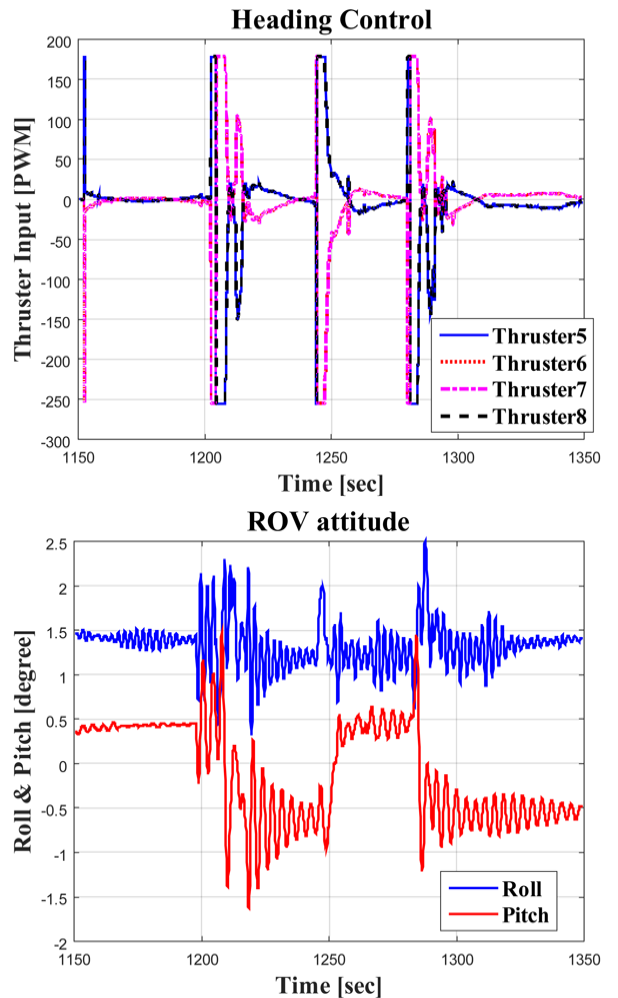

Fig. 11 Experiment data with changed reference heading and fixed reference depth 

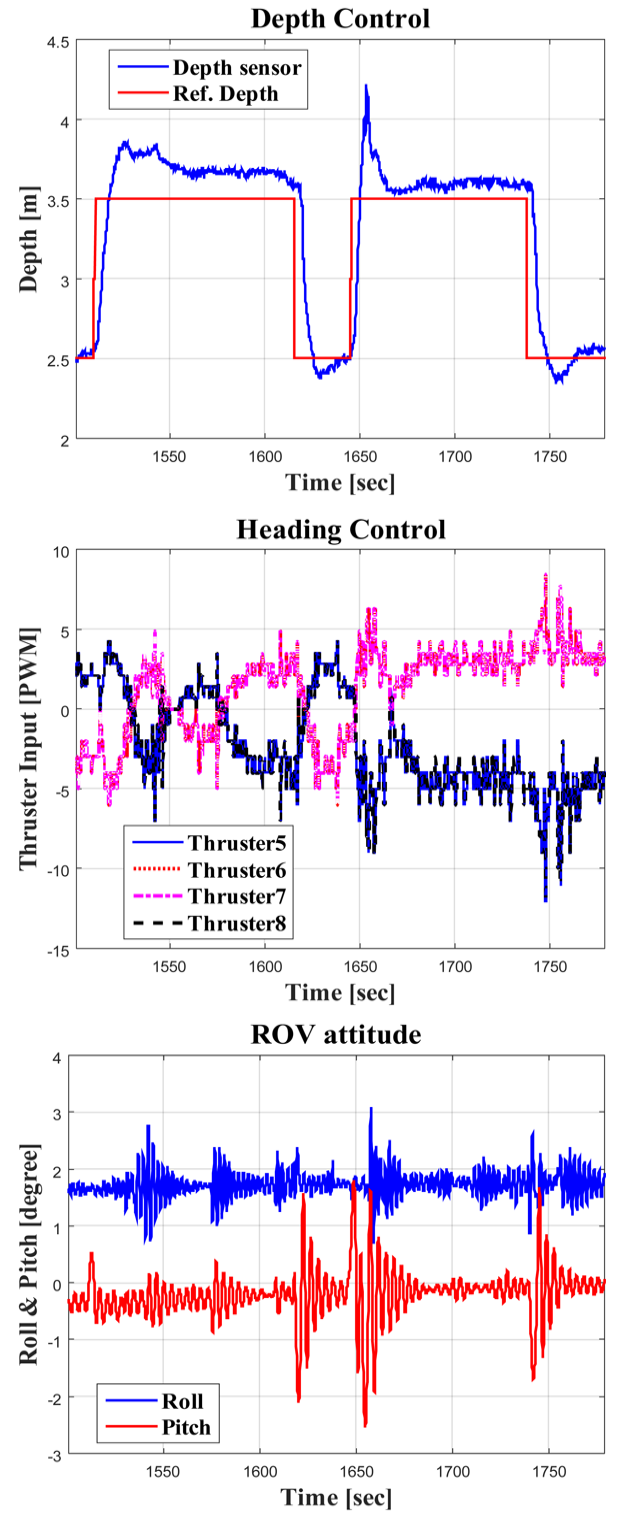
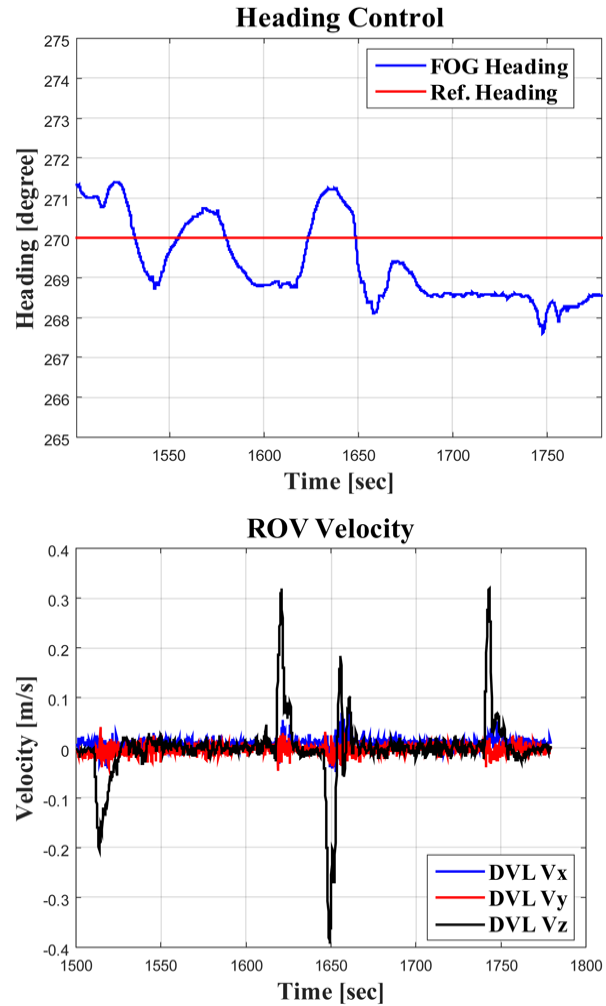

Depth Control

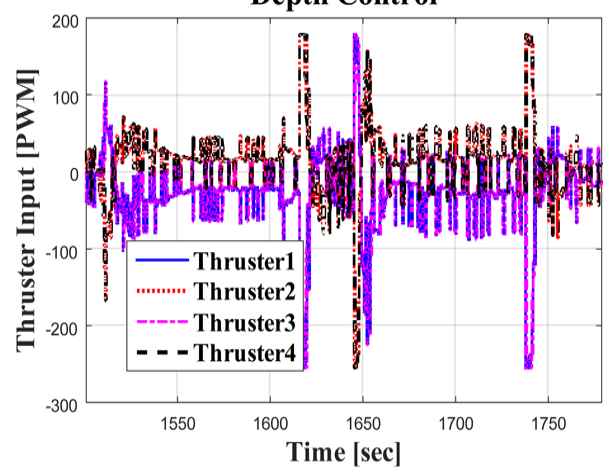

Fig. 12 Experiment data with fixed reference heading and changed reference depth

그래프에서 큰 폭으로 변하는 $\mathrm{Y}$ 축 속도와 거의 변동이 없는 $\mathrm{Z}$ 축 속도를 관측할 수 있다. 이 시험의 특이점은 우측 방향으로 선회시에는 $230^{\circ}$ 부근에서 일시적인 언더슈트가 관측되지만 좌 측 방향으로 선회시에는 관측되지 않는다는 점으로, Pitch 데이 터에서도 우측방향 선회와 좌측방향 선회시의 특징이 다르다는 것을 확인 할 수 있다. 이는 전방에 장착된 로봇팔에 영향을 받 은 것으로 예상되며, 추후 이러한 ROV의 특징을 추력배분시에 고려하고자 한다. 제어시 언더슈트가 발생하는 이유는 반복적 인 선수각의 변화는 ROV의 작업에 방해가 되므로 이를 억제하 는 방향으로 제어이득을 설정하였기 때문이다.

Fig. 12는 목표 선수각을 $270^{\circ}$ 로 고정 한 상태에서 목표 수심 을 변경한 결과이다. 이때, 수심의 목표치는 $2.5 \mathrm{~m}$ 와 $3.5 \mathrm{~m}$ 로 반 복적으로 설정되었다. 제어결과로부터 상승 및 하강시의 제어 특성이 매우 다르다는 것을 확인 할 수 있으며, 하강시에 비해 상승시의 제어 성능(정착시간, 오버슈트, 오차 등)이 더 양호함 을 관측 할 수 있다. 상승 및 하강시 특성이 다른 원인은 프로
펠러 정/역방향에 의한 추력 차이로 예상되며, 수심 제어시 정 상상태 오차는 I 제어기를 적용하여 개선할 수 있을 것으로 기 대된다. 반복적으로 수심이 변경되는 동안, 선수각은 상대적으 로 매우 작은 제어입력만으로 $\pm 3^{\circ}$ 이내에서 제어되고 있음을 관 측할 수 있다. 선수각의 변화 없이 수심만 변경했기 때문에, 속 도 그래프에서 큰 폭으로 변하는 $\mathrm{Z}$ 축 속도와 거의 변동이 없는 $\mathrm{X}, \mathrm{Y}$ 축 속도를 관측할 수 있다.

\section{5. 결 론}

본 논문은 과구동기 시스템인 경작업용 ROV의 운동을 제어 하기 위해 추력을 배분하는 상위 제어기와 선수각 및 수심 제 어를 위한 하위 제어기를 구현하고, 이를 적용한 성능시험 결과 를 제시하였다.

경작업용 $\mathrm{ROV}$ 는 수중에서 정지된 자세로 작업하기도 하고 탐사를 위해 일정한 자세를 유지하면서 이동하기도 한다. 이러 
Implementation of Heading Angle and Depth Keeping Control of ROV with Multiple Thrusters by Thrust Allocation 75

한 작업을 수행하기 위해서는 ROV의 자세가 우선적으로 제어 되어야 한다. 이를 위해, 경작업용 ROV의 추진 시스템에 대해 설명하고 추진기의 특성 분석을 위한 입출력 실험을 수행하였 다. 경작업용 ROV는 작동기가 움직일 수 있는 자유도보다 많은 과구동기 시스템이므로, 이를 통합 관리하기 위해 추력배분기 법을 적용한 상위 제어기로 원하는 운동을 개별 추진기의 추력 으로 배분하였다. 또한, ROV의 선수각 및 수심을 제어하기 위 한 하위 제어기에 PD 제어기를 적용하여 수조에서 2가지 방법 으로 실험을 수행하였다. 실험결과로부터 정지 상태에서 선수 각 및 수심이 각각 $\pm 5^{\circ}, \pm 0.2 \mathrm{~m}$ 정도의 오차를 가지며 제어되지 만, 운동 방향에 따른 특성이 다름을 확인 할 수 있었다.

향후에는 ROV의 조종성 향상을 위하여 종경사각 제어, 경로 제어, 속도제어, 외란 중 위치유지 기능 등을 개발할 예정이다. 또한 과구동기 시스템의 장점을 활용하기 위하여 추력 재배분 및 내고장성에 대한 연구를 수행할 계획이다. 이는 특정 추진기 가 추력 한계를 벗어나거나 고장 등의 문제 발생 상황에서 다 른 추진기의 여유(Redundancy) 추력을 이용하는 것으로, $\mathrm{ROV}$ 운용에 있어 응급 상황에서 필수적인 요소이다.

\section{후 기}

본 논문은 해양수산부의 국가 R\&D 사업인 '수중건설로봇공 통기술 및 경작업용 ROV 기술개발’에 의해 수행되었습니다 (PMS3700).

\section{References}

Berge, S., Fossen, T.I., 1997. Robust Control Allocation of Overactuated Ship: Experiments with a Model Ship. IFAC Proceedings Volumes, 30(22), 193-198.

Craven, P.J., Sutton, R., Burns, R.S., 1998. Control Strategies for Unmanned Underwater Vehicles. The Journal of Navigation, 51(1), 79-105.

Fossen, T.I., Johansen, T.A., 2006. A Survey of Control Allocation Methods for Ships and Underwater Vehicles. In 14th Mediterranean Conference on Control and Automation.

Garus, J., 2004, Optimization of Thrust Allocation in the Propulsion System of an Underwater Vehicle. International Journal of
Applied Mathematics and Computer Science, 14(4), 461-467. Harkegard, O., Glad, T., 2005. Resolving Actuator Redundancyoptimal Control vs. Control Allocation. Automatica, 41(1), 137-144.

Henrik, J., 2005, Optimal Thruster Actuation in High Precision Attitude and Orbit Control Systems. Master of Science Programme in Space Engineering, Lulae University of Technology.

Ji, S.W., Kim, Y.B., 2012. Control Allocation and Controller Design for Marine Vessel based on $H \infty$ Control Approach. Journal of Ocean Engineering and Technology, 26(3), 20-25.

Johansen, T.A., Fossen, T.I., 2013. Control Allocation - A Survey. Automatica, 49(5), 1087-1103.

Lee, C.M., Kim, K.H., Yoon, S.M., Kim, S.M., Byun, S.H., Moon, Y.S., 2017. A Fundamental Test of The Underwater Construction Light Work Class ROV. Proceedings of Fall Conference of the Korean Society of Ocean Engineers 2017, Busan, 231-235.

Oppenheimer, M.W., Doman, D.B., 2007. A Method for Including Control Effector Interaction in The Control Allocation Problems. AIAA Guidance, Navigation and Control Conference and Exhibit.

Pedrami, R., Wijenddra, S., Baxter, J., Gordon, B.W., 2009. A Control Allocation Approach for Energetic Swarm Control. American Control Conference, 5079-5084.

Shen, Q., Wang, D., Zhu, S., Poh, E.K., 2017. Robust Control Allocation for Spacecraft Attitude Tracking Under Actuator Faults. IEEE Transactions on Control Systems Technology, 25(3), 1068-1075.

Whitcomb, L.L., Yoerger, D.R., 1999. Preliminary Experiments in Model-based Thruster Control for Underwater Vehicle Positioning. IEEE Journal of Oceanic Engineering, 24(4), 495-506.

Yoon, S.M., Lee, C.M., Kim, K.H., Kim, S.M., Byun, S.H., Moon, Y.S., 2017. Motion Control of a Light-work-class ROV for Underwater Working: Heading and Depth Control. Proceedings of Fall Conference of the Korean Society of Ocean Engineers 2017, Busan, 244-247. 